\title{
Intuitive Mathematical Knowledge as an Essential Aspect of Contemporary Adult Learning: A case of women street vendors in the city of Gaborone
}

\author{
REBECCA NTHOGO LEKOKO and \\ KGOMOTSO GETRUDE GAREGAE
}

\begin{abstract}
The findings of a phenomenological interview study with women street vendors showed a strong link between participants' perceptions of everyday use of mathematical literacy and the speculations that mathematical use arose spontaneously in response to a practical need. The concept of intuitive mathematics as used indicates that mathematical thinking is an indispensable element of everyday conversation. Although the study finds that intuition and spontaneity are essential principles of lifelong learning, it concludes with recommendations for an empowerment curriculum that interweaves participants' experiences and intuition with formal/academic mathematical literacy and psychosocial skills necessary for success in a highly competitive business world.
\end{abstract}

\section{Introduction}

Botswana is a sparsely populated country in the Southern African region with a population of about 1.7 million, occupying a land with an area of 582,000 square kilometres (224,7 10 square miles). Like a number of countries in this region, women represent the majority of the population $(52 \%)$. Statistically, Batswana are said to be highly literate. By the year 2003, literacy rates of 77 percent for adult males and 82 percent for adult females were recorded (Molefhe 2004). Literacy in the context of Adult Basic Education in Botswana has been defined as the ability to read, write and handle simple numeric problems.

In Botswana, the Department of Non-Formal Education in the Ministry of Education is responsible for major activities relating to adult basic literacy. In this department, literacy is mainly viewed as 'a set of language and communication skills, attitudes and knowledge involving an integration of listening, speaking, reading, writing, numeracy and critical thinking which people require and can effectively use to varying degrees' (Central Statistics Office 1997:3). As it may be seen, literacy is used as a broader term that encompasses issues of numeracy. Numeracy embraces an 
adult's ability to handle simple numeric problems including the ability to handle information and to express ideas and opinions.

Most importantly, in this paper, the conceptualisation of literacy focuses on the lived experiences of street vendors as poor women who have been forced to sell in the street by circumstances beyond their control (Freire 1973). These women are disadvantaged in a number of respects. Many of them are victims of a patriarchal Botswana society. Kincheloe (1999:269) purports that the original use of the term 'patriarchy' meant control by the father. This implies that some women are controlled and oppressed by their male counterparts. Many men, for example, who abandon their families or obtain a divorce, refuse to offer assistance to the wife and children left behind, thus leaving women alone with the burden of fending for the children. At times, the women left behind are helpless in the sense that the men had been the bread winners. In addition, a number of girls still drop out of school due to pregnancy (Bhusuman 1994, Republic of Botswana 2001). This increases the number of children born out of wedlock and hence the number of irresponsible fathers. These are some of the factors that push women to go to the street to sell, with the goal of fending for their families.

Most of the street vendors are either illiterate or semi-literate. The term semi-literate is used simply here to refer to people who did not successfully complete their basic education. In the Botswana context, adult basic education starts from Standard 1 (Grade 1), that is, first year of elementary schooling, to Form 3 (Grade 10). It is a ten-year program. Elementary schooling is seven years and junior secondary runs for three years. Some have dropped out in the process of doing the ten-year basic education program. Thus, these women use mathematics in context, guided mostly by their natural ability to handle numbers (Johnston 2002:4). As a result, street vendors are considered literate to the extent that they can communicate well with their customers; they display attitudes that facilitate their buying and selling business; they can read and write to address the challenges of their businesses; and they can enumerate and use critical thinking well (Central Statistics Office 1997:3). The idea of numeracy as presented here has been reflected in the Botswana future vision, which states that by the year 2016, Botswana would have citizens who are able to read, write and enumerate, as required by the local environmental challenges to adjust to the changing world (Republic of Botswanna 2004). Women street vendors are citizens who cannot be left behind in our journey to an educated, informed and productive nation. Literacy and numeracy are not only essential for these street vendors, but they are considered critical aspects of a growing and vibrant economy. 


\section{Background to the study}

In this era 'no one can do entirely without cash' (Skjonsberg 1995: 225). Using cash involves working with numbers. Numbers are critical components of numeracy. Calculations such as subtraction, addition, division and multiplication, are examples of numeracy practices. Thus, the focus of this paper is on mathematical literacy, especially that of using numbers, as applied daily by women street vendors. As will be demonstrated, the women street vendors who participated in the study knew a great deal about their business, especially handling money. They added, counted and subtracted, and what they did was intuitive. Johnston (2002) makes us aware that numerate behavior involves solving a problem in a real context. In the case of street vendors, real contexts mean selling and buying, that is, business transactions.

Mathematical skills are applied in many daily chores like cooking, dressmaking, ironing and shopping (Lave 1988, Manyika 2002, Garegae 2004). In most of these cases, people need not go to school to attain formal mathematical knowledge; instead, they can use informal strategies for calculations and this is what most street vendors in Botswana use. Lave's (1988) study, for example, showcases the use of informal calculation strategies mostly employed by women in their day-to-day buying activities. She concluded that the way these shoppers applied mathematics when calculating was different from the scholarly (formal or academic) ways of calculating. They only engage in meaningful calculations when there is a problem to solve. Manyika's (2002) study in Botswana, similarly to Lave's (1988), discovered that housewives and street-vendors also apply what can be referred to as functional mathematics. That is, they can see meaning in numbers when applied to their own problems.

Overall, it is believed that people deal with numbers to respond to their specific real life needs or situations. In the African culture, for example, when Africans reckon time, it is for a concrete and specific purpose, in connection with events, not just for the sake of mathematics (Mbiti 1988). One example of this kind of mathematics use is with calendars in the traditional African situation. As Mbiti (1988) purports, originally, numerical calendars did not exist in African traditional societies. Instead of numerical calendars, there are what one would call phenomenon calendars, in which events or phenomena which constitute time are reckoned or considered in relation with one another and as they take place. For example, an expectant mother counts the lunar months of her pregnancy; a traveler counts the number of days it takes to walk from one part of the country to another. The day, the month, the year - are reckoned according to their specific events, for it is these that make them meaningful (Mbiti 1988:17). 
It is against this background that one tends to agree with Zaslavsky (1992) that there is no reason why one type of mathematics - formal should be more valid than the other type - informal. There are people who can count and yet do not have academic literacy or numeracy education. Women, for example, have been credited as the first mathematicians because they were able to keep records of their cycle of menstruation before being exposed to formal mathematics (Kellerm 2005). Zaslavsky (1992), for example, reported lunar markings found on prehistoric bone fragments showing how early women marked their menstruation cycles. These are examples of informal mathematics used in specific cultural contexts. Furthermore, some people can tailor clothes to very precise measurements without having attained the necessary formal mathematical skills to do that. More examples can be given to show that mathematics is an indispensable part of everyday activities. Failure to realise this natural use may result in failure to acknowledge the contextual and intuitive use of mathematics by women street vendors.

\section{The study}

Informal mathematical use is part of day-to-day activities. At times one may apply it and not be aware of its application. For example, when walking or driving, people memorise routes and trajectories. All these involve the use of informal mathematics (Manyika 2002). When, for example, we classify, order, select and memorise some things, we employ mathematics concepts. Similarly, the type of mathematical operations considered in this study is informal mathematics. This entails generating, organising and using oral mathematical constructs to address an immediate challenge in the real life situations of buying and selling.

Learning that is intuitive leads to lifelong literacy. It is life-long because it is applied to real-life circumstances and as such it is not easily forgotten. Learning continues throughout the times of the women street vendors' business. For example, techniques such as counting, ordering, sorting, measuring, weighing and classifying are used by these women vendors on a daily basis. As these techniques are used regularly, they are refined and retained, to be used again and again in later life situations. The main goals of the study, therefore, were to find out how street vendors perform their calculations or deal with problems of calculations whenever they occur, and to explore the process of finding ad hoc solutions to calculation problems. 


\section{The study site}

The study was carried out in Gaborone, the capital city of Botswana, a vibrant and colorful city which is primarily an administrative centre with government offices. It is the main centre for commercial, shopping, banking and telecommunication facilities. It also has a small manufacturing sector that produces metal and wood items, and beer. Within the city centre, there is the National Museum and Art Gallery. In addition, the city is the headquarters of all Government offices and some private institutions. The city is expanding rapidly, with the number of unemployed people growing, as many people leave the rural areas and come to Gaborone with the hope of gaining paid employment. When employment is not forthcoming, many people resort to other means of getting money, in most cases, selling on the streets.

\section{The urban vending scene: Gaborone Gity}

Street vendors can be described as 'traders of any type of goods and services, which may include: fruits and vegetables, newspapers, cosmetics, jewelry, watches, bags and wallets, second-hand clothes' (Jimu 2004:19). The women street vendors in Gaborone mainly concentrate on selling food stuff, including fruits and vegetables. Street vending falls under the informal employment sector. As could be expected, street vending attracts consumers of low class, the low paid and non-working class. Some of these people go to the street thinking they can get cheaper goods since they cannot afford to buy expensive things from supermarkets and convenience shops.

Wherever they are found, street vendors are strategically located where customers will easily spot them. In the case of Gaborone, these people are mainly seen in big malls and shopping centers, and along main roads (such as in the street leading to the University of Botswana) where they are sure they will be seen by a number of passersby. Other places that attract street vending are residential places, especially the low, medium cost housing areas and squatter camps. Also, bus/taxi ranks, petrol stations, motor vehicle garages, as well as school sites and industrial sites, are targets for the vendors. Most vendors sell products ranging from food-stuffs to traditional herbs. As Scott (1999) noted, this service is one of the mutually rewarding services to Batswana women. Because of the contributions women vendors make to the economy, as well as to their family lives, they consider themselves entrepreneurs, not petty vendors as they are sometimes referred to (Malema 2004).

Some street vendors obtain proper licences to trade. Others do not. Thus, the existence of illegal vending makes it difficult for the city council to monitor the growth and quality of this industry. Some vendors reside in Gaborone while others come from the surrounding areas such as 
Molepolole, Moshupa, Mochudi and Kanye. Some of these villages are about $100 \mathrm{~km}$ away from Gaborone. Some street vendors are foreigners. This group sells cheap textiles, musical products, vegetables and food (Sithole 2004).

The rate at which this sector grows has been a great concern for the City officials. Established businesses, and some visitors too, have expressed concern over this growth and the laxity of its management (Malema 2004). Other businesses, for example those in the railway station, the city centre and the long distance bus terminal, as well as other shop owners, believe that these vendors are stealing their business, especially since some of these vendors are trading illegally. There is, therefore, the need for strong legal documents to facilitate and regulate the vending businesses. If not well regulated, illegal vending can hamper other businesses.

While some street vendors welcome government/legal intervention others still resist. Conflicts have thus arisen between city council officials and the street vendors. A recent case, in January 2005, occurred in the city of Francistown where some street vendors found their cubicles removed and dumped in the trash pit. Officials alleged that on several occasions they had asked the vendors to move out of that self-allocated plot, but they did not pay heed to the warning. This, as already said, was not the first incident in which street vendors clashed with the law. Some disgruntlement of a different nature also occurred in the city of Gaborone in 2002 when about 2000 demonstrators shut down their operations and participated 'in the first ever big march in the history of the country by the informal sector' (Mmegi 2004). In their petition, which was read out to the then Local Government Minister, the angry demonstrators accused the Gaborone City Council and the police of harassment and confiscation of their goods, hence denying them 'a source of living' (Mmegi 2004). In the petition, they categorically stated that 'the city council and the police are terrorising us from our operating centers, hence, we are constantly on the move; they are also confiscating our goods' (Mmegi 2004). Included in the demonstration were other workers from the informal sector; street cooks, barbers, hairdressers, cobblers and itinerant fruit packers who braved the sweltering heat to join the march (Mmegi 2004). It is not, however, known how the informal sector benefited from this 2002 march. What is known is that, to date, conflict between the city officials and street vendors continues.

\section{Research design and methodology}

A qualitative research paradigm, phenomenology, was employed in this study. An important underlying principle of phenomenology is that 'researchers need to explore evidence of the world not as it is thought to be, but as lived' (Morse and Richards 2002:45). It was within the framework of this principle that the lived experiences of street vendors were sought. The 
goal was to solicit the active participation of women who are vending in the street of Gaborone and to be certain that it was indeed their everyday life experiences that were being explored. We studied the daily selling and buying businesses of nine women street vendors in the city of Gaborone.

The use of phenomenological interviewing enabled us to go into the 'business world' of the women street vendors, to observe, to discuss with them and understand their use of mathematical calculations. The researchers believed that women street vendors held unique experiences about the concrete situations of their daily business of selling and buying. Thus, the goal was to approach them and obtain from them their experiences of mathematics in context. Some in-depth phenomenological interviewing was conducted. For the researchers, interviewing was very important. First, as inquisitive explorers, the interactive interviewing provided opportunities for them to ask a number of questions within the natural settings of these vendors - ie their business locations. They were able to get good and informed insights into the circumstances of the street vendors' selling and buying business.

It must be noted that an appreciation and understanding of the world of business for the women was important for us as phenomenologists because it provided opportunities to participate in the actual life-world and to share experiences with participants. An in-depth examination and probing of these women's lived experiences started with a question: 'What is it like to be a woman street vendor in the city of Gaborone?' Researchers and participants became active communicative partners as these women shared their experiences and the challenges of their businesses. The interview was a 'curious bilateral relationship' (Glesne and Peshkin 1992:83) in which researchers became sensitive to the participants' real experiences of selling and buying and the participants too responded to the questions posed and the probes that followed.

\section{Selection and sampling}

In this study, purposive sampling was employed. Maxwell (1996) defines purposive sampling as a "strategy in which particular settings, persons or events are selected deliberately" (69). Based on this principle of purposefulness, the researchers selected Gaborone, a site that is convenient in a number of respects. First, Gaborone is place of both residence and work for the researchers, so it was convenient for them to visit the selected street vending site, especially at a time that did not interfere with their regular teaching responsibilities. Purposive sampling was also suitable for this study because researchers needed to choose a few participants who were strikingly different in terms of their location of selling and the items being sold, as well as their target customers. These factors determined the nature of the experiences these women would have about their businesses. Also, as this 
study was self-sponsored, researchers chose one site in Gaborone because they could afford (financially) to visit it as many times as they found necessary. This was not going to be possible should they have made decisions to explore more than one site.

To select the participants, a purposive strategy was used. Women street vendors had rich experiences which when explored could satisfy the purpose of carrying out this study, that of exploring street vendors' use of intuitive mathematics. It was necessary that the research be blended with what was happening in the street vending scene, thus the interviews were conducted at these women's day-to-day buying and selling locations. The women who participated 'were centrally involved with the phenomenon, and have many life experiences to talk about' (Becker 1986:105). They were in the business for two or more years. To gain insight into the daily selling and buying businesses of these women both amongst themselves, and between them and customers, researchers visited businesses at a time when a significant number of customers might come. This allowed them to witness a number of transactions being made.

\section{Procedures}

\section{Data collection}

Phenomenological interviews were conducted with each participant. A semi-structured interview guide was used which enabled the researchers to pose similar questions to each of the respondents. The way the questions were framed, for example, "What challenges do you sometimes meet in your business?' opened for probing when the researchers felt that the responses given needed to be elaborated. Participants were free to talk about their experiences, especially given that the interviewing was conducted in a familiar place and using their day-to-day language of communication. Participants used Setswana, which is their first as well as the national language. Using the language they were familiar with also gave them a democratic atmosphere in which to express their opinions and to communicate with their customers freely. Researchers were, therefore, privileged to listen to these women as they described the dynamics of their businesses and as they encountered situations requiring them to use their mathematical knowledge. Each participant was visited and interviewed three times. The first interview was actually the time for researchers to establish rapport with participants and subsequent visits were for the purpose of doing in-depth interviewing coupled with some observations.

\section{Data analysis}

Following the three levels of coding, namely, open, axial and selective (Bogdan and Biklen 1992, Strauss and Corbin 1998), a number of themes 
emerged around which the discussion in this paper is presented. The themes capture relevant information about the phenomenon of the study, that is, the use of intuitive mathematics by women street vendors in the city of Gaborone. Coding was also done using Bogdan and Biklen's (1992) folder approach to data synthesis. In this approach, data with similar topics were cut into pieces and placed into one envelope. Data in each folder were then re-read and arranged into themes and categories.

\section{Findings}

\section{The spirit of corporate-ness}

The findings shed light on how the African traditional 'culture of corporate - to be human is to belong to the whole' (Mbiti 1988:2), has had an impact on the way women street vendors related to each other. In the African culture, people are socialised to believe that 'to be human is to be part of a community.' Women vending close to each other regarded themselves as a community of sellers and being a community to them meant participating in each other's activities and helping each other. As one of them indicated:

I am a relative newcomer to this compared to these others. Back when I was just thinking of selling, I kept on thinking about the oldies in the business and would start wondering how they would treat and look at me as a newcomer to their business. I feared that they might feel that I am taking their business away from them. I couldn't start right away because every time I thought of starting, I would let my fears get the better of me. Finally, I decided that if I get in, I get in. After joining, I realised that these women (pointing to other women vendors) are selfless helpers, patient and tolerant to a new comer. I am glad I found a community to belong to. Yes, we work together and we are a community.

The vendor further explained that this was her first opportunity to express openly her feelings of appreciation of the other vendors. What we see reflected in the above quotation is that an African person rarely detaches himself or herself from people around her or him, be it due to business or any other occupations in their lives, 'for to do so is to be severed from his roots, his foundation, his context of security' (Mbiti 1988:2) and can amount to self-excommunication from people who can assist in times of need. Generally, other vendors expressed similar sentiments of the need to be 'sisters in business'.

The women vendors interviewed were aware that the growth and sustenance of their business did not solely depend on the owner, but on everyone with an interest in helping it grow. This type of attitude is what we 
refer to as a 'culture of corporateness.' For example, when one of these women vendors was asked how she coped with her business, she expressed the fact that other women had been helpful. At times, after buying some new items, she was not sure how much to price them 'I just see how much I bought them for and price according to the price of other vendors.' But before making the final decisions, she asked them for advice. The whole environment of their selling gives a feeling of togetherness which also gives way to a feeling of security. Any one of them felt it safe to leave her business for a short time with another one in the group, especially when there was some emergency to attend to. It can, therefore, be concluded that the interviewed vendors in the streets of Gaborone do not completely eschew their cultural heritage. Traditionally, Batswana do not encourage anyone to do things solo, as reflected by proverbs such as Kgetsi ya tsie e kgonwa ke go tswharaganelwa, (the more hands, the easier to carry a [heavy] bag of locusts - literally translated). Thus, some of the basic underlying principles of the selling and buying for these women are cooperation, collaboration and sharing.

\section{Principles of self-organisation}

Participants in this study demonstrated an impressive level of selforganisation. Self-organisation here implies the ability to team up when a challenge requiring attention by more than one person comes up. For them, organisation is something that has to come spontaneously. Spontaneity here implies a 'natural instinct' to want to work with others. The importance of spontaneous self-organisation for women street vendors was demonstrated in a number of conversations such as:

I usually go to someone who would not put me down; someone with a smiling face and someone who seems to be mature enough to understand that as human beings we can't be jacks of all trades. But you know, some people forget themselves and think that they are complete.

As implied in this quotation, there are some qualities that attract one vendor to partner with another vendor. It is important for these women to work with a vendor they accept.

However, participants also expressed that working collaboratively is something that they do in their own cultures (at home, in schools, churches, and the community at large). To this effect, one participant stated that:

We Batswana women, we consider ourselves sisters. We therefore like to work in harmonious relationships. Kana, we are born in interactive environments. We have siblings, friends and others that we may meet in the street. It is important for us to develop friendship so that in times of troubles and challenges we can sympathise and help each other. We meet new people 
all the time, in all these situations, we use our in-born capacity to relate and work together in a smooth manner.

In further probing, it emerged that these women are motivated by certain qualities to work with each other. Qualities such as friendliness, humility, open-mindedness and maturity were cited by the vendors. An interesting observation as we listened to these women was that they seemed to echo Shotter's sentiment that in 'everyday life activities, we must interlace our actions in with those of others, their actions will determine our conduct just as much as anything within ourselves' (Shotter 1993b:174).

\section{Reciprocal conversation}

One of the interesting situations of these women street vendors was that they spent most of the time talking to each other, especially during light days (that is, when consumers are few). When asked what they normally talk about, they delightedly explained how their talking together was not just passing time but mostly focused on their experiences as street vendors. During the time we did the interviews, there were some concerns from officials that vending should be strictly regulated, licensed and moved to a designated market. For that week and subsequently, these women were discussing this issue. They talked about the implications of what the officials were proposing. For example, they reacted to the suggestions that their sites be moved to a different location. Thus, when these women engage in conversation, it is not empty talk. It is a conversation full of issues germane to their business world.

These women also talked about monetary transactions. Botswana uses Pula (P) and Thebe (T). One Pula is an equivalent of 100 Thebe. As an illustration, a conversation between one vendor and a customer is described below:

A customer wanted to buy from her but she did not have change for a P50 bill. The customer wanted to buy two combs of maize at P2.50 each; two melons, one at P9.00 and the other at P8.00. She signaled (waving the P50 bill) to the other vendors indicating that she needed some help with change. After explaining to one vendor who volunteered to help her, she received the following notes and coins: a 20 Pula note, two 10 Pula notes, four 2 Pula coins and four 50 Thebe coins. Upon receiving the changed money, she immediately placed a 20 Pula note in the hand of the customer and explained that she was certain the customer's change was more than the 20 Pula note. She proceeded by arranging/separating two sets of P2.50 coins - the exact amount for the payment of two maize combs. As far as the payment of the two melons was concerned, she started working the change for the first melon costing P9.00. She took a 10 Pula note and gave back the customer two 50 Thebe coins (P1.00). The final transaction was for a 
melon costing P8.00. To work out the change for the customer, the vendor took another 10 Pula note and placed it in her purse-basket and took as change one 2 Pula coin. What remained in the plate were two 2 Pula coins, and two 50 Thebe coins. These were given back to the customer. The transaction was then completed.

Notably, this transaction involved only oral mathematics; nothing was written down. Thus, conversation/oral communication constitutes an important aspect of the selling and buying business of the women street vendors. As they went through their calculations, the customer was being talked to so as to help the two of them (seller and buyer) to understand the transactions. They verbalised the calculation processes. For the women street vendors, oral mathematics formed an inseparable part of their day-today discussion; it was there in all situations.

\title{
Mathematical communication is part of our day-to-day activities
}

A major theme that emerged from the study was that women street vendors engaged in mathematical conversation on daily basis. Since they were dealing with problems of selling and buying, they found themselves manipulating quantitative information in their minds. The manipulation of figures was done through verbal exchange. This finding, too, concurred with Shotter's (1993a) conclusion that our daily lives are not rooted in written texts or in a contemplative reflection, but in oral encounters and reciprocal speech. In other words, we 'live our daily lives within an ambience of conversation, discussion, argumentation, negotiations, criticism and justification' (Shotter, 1993b:29). The women vendors demonstrated this usefulness of the conversation. A quotation such as the one presented below reflects the value that women gave to their conversation:

\begin{abstract}
Since some amongst us are more experienced in this area, we talk to them asking them if we are not really cheating ourselves. For instance, one day I told my neighbour that I have bought a box of 150 red apples at P72.95 and am intending to sell them at P1.50 each. She asked me why I want to sell them at P1.50 instead of P1.00? We started analyzing my pricing through verbal exchange.
\end{abstract}

There was ample evidence from our conversations with the women vendors that indeed conversation is the pillar of their selling and buying businesses. When asked if their conversations at times interfered with their businesses, one of them responded: 
Our discussions don't stop us from attending to customers; our conversations sometimes take a long time before we can understand each other. But, since we realise the importance of discussion, it does not matter how long it takes one to be helped. And because each day has its own problems, we find ourselves discussing similar issues on daily basis. We even advise each other where to get the stuff relatively cheaper.

The above quotations reveal that mathematical exchange is indeed part of the daily conversation of the women vendors, and it is through this conversation that this particular vendor copes in the field.

\section{Discussion and summary}

What follows are possible suggestions about how women street vendors' intuitive knowledge can be used to complement their formal training. The findings of the study indicate that when women street vendors encounter real-life mathematical challenges in their daily buying and selling business, they cope by using conversational mathematics (oral and mental mathematics). Most of the knowledge they use is not attained from formal schooling systems but it is termed 'intuitive mathematics'. This is the type of knowledge used to respond to the real life challenges of their businesses. Intuition denotes spontaneity. When, for example, one of the women was confused about how to calculate change for a customer, mediators were readily available to help.

While it is acknowledged that oral or mental calculations are important in the lives of these street vendors, it also has to be acknowledged that some formal mathematical skills and competency are essential too. The acquisition of such skills should occur in a highly practical and contextualised situation. Street vendors are lifelong learners. The lifelong learners' greatest passion is to see how what they learn works in real-life situations. Immediacy of application is important to lifelong learners because putting an idea into practice provides a unique insight into how what has been learned can be modified to suit the changing situations. Thus, what matters in their training is to be equipped with skills to satisfy the immediate needs of their businesses.

It is also worth noting that business for the women vendors was considered to be something that needs collective thinking or helping each other. To think that a single individual person can deal with it on his or her own without the involvement of others contradicts the African tradition of corporateness - 'I am because you are and you are because I am' (Mbiti 1988:106). Thus, it is maintained that a business is a collective endeavor that opens the doors to working together and helping each other, in order for the business to grow. While the cultural thinking of these women should be appreciated, at the same time, the shortcomings of such thinking need to be 
explored. The discussion that follows addresses the need to use the informal practices to strengthen the formal learning so that these women are well equipped to handle the challenges of their businesses.

\section{Conclusions and recommendations}

In this paper, the discussion tends to focus on how street vendors use mathematical operations in their daily business. Mainly, they engage in the use of numbers. For example, they count the number of items sold or bought; they count the worth of money they get; they count how much change to give and they count how much money they have in their hands. However, counting is not the only mathematical skill they use. Selling and buying also involve arithmetic operations of addition, subtraction, division and multiplication. Johnston (2002:4), for example, defines numeracy as 'the ability to perform arithmetic operations using numbers in real life context' and this is what street vendors do on their daily business operations.

Against the background given above, there seem to be some problems in the use of intuitive mathematics alone, in as far as the selling and buying business of the women street vendors is concerned. One problem that we discovered was that these women vendors did not have clear guideposts to tell them how well they were doing and no clear outcomes to judge the profitability of their businesses. For example, when one of these participants was asked how she worked out the profit for the day, it became apparent that days might go by without her knowing whether she was profiting from her business or not. She responded that at the end of the day, she did not work out her profit nor did she keep a daily bank deposit. Her signpost for profit was the sensing of the frequency or the number of customers who visited and bought some items from her. Some of them would count loss by the number of items that spoiled (were rotten or expired). We believe that this kind of the use of highly informal strategies of calculating profits and loss are blinkered with regard to the actual calculations. They are, therefore, likely to mislead the women vendors. We realised that there is a need to provide a way in which women street vendors can be helped to keep track of their selling and buying activities. Therefore, we suggest that book-keeping should be considered when ways to help them to be successful business women are being considered.

There is also a need to strengthen the women's mathematical skills to cope confidently with the mathematical operations required in their world of work. Two areas needing attention are mathematical literacy and psychosocial skills. Mathematics literacy as a tool for economic advancement cannot be over-emphasised. It is an ability to interpret and communicate quantitative and statistical data in different contexts. This even includes working with money. Women in this study showed a limited understanding of formal calculations. As such, they may be victims of 
cheating in everyday transactions. We therefore recommend that street vendors be given some lessons on basic arithmetic. Learning should be couched within the principles of lifelong learning: that, it has to address real life situations, as well as give learners opportunities to apply what they learn immediately and in an environment similar to their selling and buying businesses. One of the crucial elements of lifelong learning is experiencebased curriculum. Thus, if the lived experiences of these street vendors are taken into consideration when their mathematics is enhanced, learning will become a process whereby their business life is appreciated in the context of mathematics teaching. When the learning of formal mathematics touches the lived experiences of these women vendors, a new feeling of motivation can be evoked. Thus, any approach to learning for these women that ignores that intuition or any talk about intuitive mathematics, would deter their motivation and the love to learn mathematics. This means that working with oral and mental mathematical processes should be emphasised.

On the part of the psychosocial aspect of their business, we also discovered that it may not be wise for the women street vendors to continue operating on the principle of 'corporateness' as they have demonstrated. While we do not dispute the value of communication and collaboration in businesses, we nevertheless believe that these women vendors live in a competitive world of businesses in which an individual business has to position itself for competition. Thus, each individual woman street vendor has to develop capacity to keep her business going against all odds. These vendors need to understand that competitiveness is not tantamount to rivalry but is a way to improve and contribute to the growth of the business.

In sum, we recommend an economic empowerment curriculum for these women. The economic empowerment will focus the learning for these women around their lived experiences as 'poor' women. Poor here is used loosely to mean economically disadvantaged and lacking the knowledge, skills and attitudes that these women need to escape their undesirable situation (Kincheloe 1999:260). It calls for a multidimensional holistic course where women will be helped to understand their situation holistically not just in 'simply egoistic, self-centered and rationalist terms' (Kincheloe 1999:260). It should touch on the social, political, and economic aspects of the privilege vis-a-vis deprivation. They will be helped to make meaning of their lives, perhaps as people who have been disadvantaged by being born women in a patriarchal Botswana society. As Kincheloe (1999:260) contends, education for them should be education that could help each woman vendor to 'pull oneself up by one's bootstraps'. The curriculum for these women vendors should help them make 'sense of the way power works and poverty develops' (Kincheloe, 1999:260) and provide options for them to initiate the growth of their business. In short, women street vendors need 
a curriculum that will enhance their critical thinking and the motivation to want to struggle, to escape the situation that they feel uncomfortable with. This is a curriculum for lifelong learning.

\section{References}

Becker, C S (1986) Interviewing in Human Science, Methods, vol 1, pp 192-124.

Bhusuman, D (1994) Teacher and Administrators' Attitudes and Perceptions of Barriers and Strategies Towards the Advancement of Women in Education Administration in Botswana, unpublished Master in Education Thesis, University of Edmonton, Alberta, Canada.

Central Statistics Office/ Department of Non-Formal Education (1997) Report of the First National Survey on Literacy in Botswana. Literacy Survey Report 1993, The Department of Printing and Publishing Services, Gaborone.

Bogdan, R and Biklen, S (1992) Qualitative Research in Education: An introduction to theory and practice, Allyn and Bacon, Boston.

Freire, P (1973) Education for Critical Consciousness, The Continuum, New York.

Garaegae, K G (2004) The Role of Mathematics Education in Poverty Reduction: An investigation on female street hawkers, paper presented at the Conference on Adult Education and Poverty Reduction: A global priority, University of Botswana, Gaborone, 14 - 16 June, retrieved on 31 January 2007 from www.gla.ac.uk/centres/cradall/docs/Botswanapapers/garegaefinal_29.pdf.

Glesne, C and Peshkin, A (1992) Becoming Qualitative Researchers: An introduction, Longman, Urbana-Champaign.

Jimu, I M (2004) An Exploration of Street Vending's Contribution Towards Botswana's Vision of prosperity for All by 2016, Pula: Botswana fournal of African Studies, vol 18, no 10, pp 10-30.

Johnston, B (2002) Numeracy in the Making: Twenty years of Australian adult numeracy, retrieved on May 16th 2006 from http://www.staff.vu.edu.au/alnarc/publications/02Johnston.pdf

Kellerm, J (2005). Women and the Origin of Mathematics, retrieved on March 3, 2005, from www.tacomacc.edu/home/jkellerm/Ethnomath/FirstMath.htm.

Kincheloe , J L (1999) How Do We Tell the Workers? The socioeconomic foundations of work and vocational education, Westview Press, Boulder, Colorado.

Lave, J (1988) Cognition in Practice: Mind, mathematics and culture in everyday practice, Cambridge University Press, Cambridge. 
Manyika, L M (2002) An Investigation on the Skills in Botswana's Junior Secondary School Curriculum in Relation to the World of Work: The case of street-vendors and housewives, unpublished Bachelor of Education Thesis, University of Botswana, Gaborone.

Maxwell, J (1996) Qualitative Research Design: An interactive approach, Sage, Thousand Oaks.

Mbiti, J S (1988) African Religions and Philosophy, Heinemann, London.

Malema, P, ed (2004) Street Vendors Demonstrate Over Harassment, Mmegi Business Week, vol 21, no 24, Friday 13 February.

Morse, J and Richards, L (2002) Readme First: For a user's guide to qualitative methods, Sage, Thousand Oaks.

Republic of Botswana (2001) Education Statistics, Government Printer, Gaborone.

Republic of Botswana, Presidential Task Force (2004) Vision 2016: Towards prosperity for all, Government Printers, Gaborone, downloaded on 30 March 2007 from www.vision2016.co.bw/PDF\%27s/English\%20Full\%20version. pdf.

Scott, E P (1999) Women Caterers: Gaborone colorful street-side restaurants, Focus Newesletter, January 1.

Shotter, J (1993a) Conversational Realities: Constructing life through language, Sage, Thousand Oaks.

Shotter, J (1993b) Cultural Politics of Everyday Life. Berrett-Koehler, San Francisco.

Skjonsberg, E (1995) Documenting Women's Views Through Participatory Research Diaries of Daily Activities in Rural Zambia, in Fahy Bryceson, Deborah, ed, Women Wielding the Hoe: Lessons from Rural Africa for feminist theory and development practice, Berg Publishers, Oxford, pp 225-236.

Straus, A and Corbin, J (1998) Basics of Qualitative Research: Techniques and procedures for developing grounded theory, Sage, Thousand Oaks.

Zaslavsky, C (1992) Women as the First Mathematicians, International Study Groups on Ethnomathematics Newsletter, vol 7, no 1, retrieved on January 1, 2005 from http://web.nmsu.edu/ pscott/isgem71.htmF. 
